\title{
Removal of oil from polymer-produced water by using flotation process and statistical modelling
}

\author{
Ku Esyra Hani Ku Ishak ${ }^{1} \cdot$ Mohammed Abdalla Ayoub $^{1}$
}

Received: 2 October 2018 / Accepted: 8 May 2019 / Published online: 14 May 2019

(c) The Author(s) 2019

\begin{abstract}
The objective of this study is to optimise the flotation process that separates crude oil and water from anionic polymer (GLP100) via response surface methodology. Hence, a model was developed to describe the efficiency of oil removal under the influence of GLP-100 concentration, gas flowrate, and duration of flotation. Confirmatory experiments were performed to validate the model at a randomly selected point which was at $450 \mathrm{ppm}$ of polymer concentration. At this point, the optimum values of the flotation parameters were recorded: $3 \mathrm{~L} / \mathrm{min}$ of gas flowrate and $6 \mathrm{~min}$ of flotation time with $99 \%$ efficiency. The predicted values seemed to match the actual value with standard deviation $0.252 \%$. The outcomes prove that this model can be used to optimise the flotation process in the presence of GLP-100 polymer.
\end{abstract}

Keywords Oil removal · Polymer-produced water · Produced water treatment $\cdot$ Response surface methodology

$\begin{array}{ll}\text { Abbreviations } \\ \text { AAPE } & \text { Absolute average percentage error } \\ \text { ANOVA } & \text { Analysis of variance } \\ \text { CEOR } & \text { Chemical Enhanced Oil Recovery } \\ \text { HPAM } & \text { Hydrolysed polyacrylamide } \\ \text { STD } & \text { Standard deviation } \\ \text { List of symbols } \\ v & \text { Velocity of oil droplets rising } \\ R & \text { Radius of the oil droplets } \\ \rho & \text { Density } \\ \mu & \text { Viscosity } \\ \varepsilon & \text { Efficiency } \\ C_{\text {underflow }} & \text { Oil concentration in the effluent } \\ C_{\text {inlet }} & \text { Oil concentration at the inlet }\end{array}$

\section{Introduction}

In oil recovery process, water can be injected into well to drive crude oil out to the surface. This process is called the water flooding process. Nevertheless, the content of oil in the reservoir would decrease after some time, and in order to improve this oil recovery process, chemicals are added

Mohammed Abdalla Ayoub

abdalla.ayoub@utp.edu.my

1 Petroleum Engineering Department, Universiti Teknologi PETRONAS, Seri Iskandar, Perak, Malaysia with the injected water, which is often called Chemical Enhanced Oil Recovery (CEOR) (Liu et al. 2005). These chemicals have an impact on the produced water treatment system (Wang et al. 2011). Treating this produced water to the environmental specification in the offshore operations is crucial prior to discharging the water into the ocean. One type of CEOR refers to the injection of surfactant and polymer flooding so as to increase oil sweeping efficiency and oil recovery.

The conventional produced water treatment system is composed of primary, secondary, and tertiary systems (Almaamari et al. 2014). The primary system includes the function of gravity separator in removing oil and solid particles from the produced fluid. Next, the secondary separator applies hydrocyclone and flotation unit to discard large and small oil droplets. Lastly, the tertiary separator embeds nutshell media filters for dissolved matter removal. In the flotation unit, the presence of gas bubbles enhances the floatability of oil and minimises separation time (Eftekhardadkhah et al. 2015). Thus, it is essential to optimise flotation parameters, such as gas flowrate, feed flowrate, gas bubble size, duration of flotation, and temperature, in order to enhance the efficiency of oil removal. The fundamental of oil and water separation is based on the Stokes' law, as expressed in Eq. 1. Stokes' law defines that the (v) velocity of oil droplets rising to the surface is proportional to the radius of the oil droplets $\left(R^{2}\right)$. The variance in density between oil and water $\left(\rho_{2}-\rho_{1}\right)$ is inversely proportional to water viscosity $(\mu)$. This equation indicates that

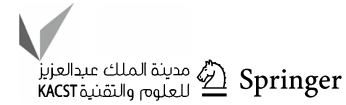


the larger the size of oil droplets, the greater the velocity. Wider variance in density enhances the aspect of velocity, while lower viscosity increases the vertical velocity and enhances the separation process (Stewart and Arnold 2008).

As for the flotation process, the generated gas bubbles increase the density between the continuous and dispersed phases, hence increasing velocity (Eftekhardadkhah et al. 2015).

$v=\frac{2}{9} \frac{R^{2}\left(\rho_{2}-\rho_{1}\right)}{\mu}$.

In fact, four steps can determine the effectiveness of a gas flotation system, as follows (Strickland 1980; Dalmazzone et al. 2012):

(a) generation of gas bubbles

(b) collision between gas bubbles and oil droplets

(c) attachment of gas bubbles with oil droplets

(d) rise of the attachments to the surface

The collision between oil droplets and gas bubbles depends on gas flowrate (Hosseinzadeh et al. 2013; Ran et al. 2013), distribution size of gas bubbles, and size of oil droplets (da Silva et al. 2015). At a high gas flowrate, more gas bubbles are generated, hence increasing the probability of collision. Nonetheless, gas flowrate that exceeds the optimum value may cause a turbulent flow that decreases the efficiency of separation (Ran et al. 2013). Thus, it is integral to determine an optimum flowrate so as to increase the efficiency of oil removal. Prior studies that investigated the effect of viscosity on the size of gas bubbles showed that increment in viscosity does not only decrease the breakup rate of gas bubbles but also increases the size (Mackul'ak et al. 2009; O'Connor et al. 1990).

While many researches have examined the effect of flotation parameters on oil and water separation (Moosai and Dawe 2003; Multon and Viraraghavan 2008; Radzi and Aliff 2017; Etchepare et al. 2017; Atarah 2011; Xu et al. 2014), only a handful have evaluated the impact of flotation parameters upon oil and water separation with the presence of GLP-100, an anionic type of polymer. Hence, this study looked into optimising the flotation process to discard crude oil from GLP-100-produced water. The Dulang crude oil was used in this study. The effect of GLP-100 concentration, gas flowrate, and duration of flotation was studied and optimised to achieve maximum efficiency of oil removal by using the RSM approach. In addition, analysis of variance (ANOVA), a statistical analysis, was performed to generate the best equation that describes the efficiency of oil removal in the flotation unit with the presence of GLP-100.
Table 1 Brine compositions

\begin{tabular}{lr}
\hline Salts & \multicolumn{1}{l}{$\mathrm{g} / \mathrm{L}$} \\
\hline $\mathrm{CaCl}_{2} \cdot\left(\mathrm{H}_{2} \mathrm{O}\right)_{2}$ & 0.7251 \\
$\mathrm{MgCl}_{2} \cdot\left(\mathrm{H}_{2} \mathrm{O}\right)_{6}$ & 0.7726 \\
$\mathrm{NaCl}$ & 10.0267 \\
$\mathrm{FeCl}_{3}$ & 0.0009 \\
$\mathrm{SrCl}_{2} \cdot(\mathrm{H} 2 \mathrm{O})_{6}$ & 0.0295 \\
$\mathrm{KCl}_{\mathrm{NaHCO}_{3}}$ & 0.3129 \\
$\mathrm{Na}_{2} \mathrm{SO}_{4}$ & 3.6065 \\
\hline
\end{tabular}

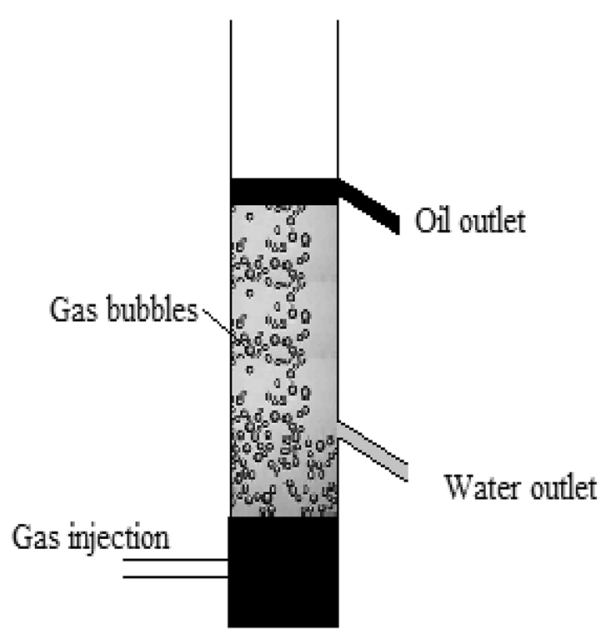

Fig. 1 Flotation unit

\section{Materials and methods}

An anionic GLP-100 polymer and Dulang crude oil with density $0.7987 \mathrm{~g} / \mathrm{cm}^{3}$ were supplied by PETRONAS Research Sdn Bhd (PRSB). The GLP-100 was in a powdery form and had light yellow colour particles. Compared to other polymers, GLP-100 is also known as temperatureand salt-resistant polymer. Therefore, GLP-100 is used in the tertiary oil recovery applications that are operating at a high temperature and having high salt reservoirs. Then, brine was prepared in accordance with the real generated water brine concentration, as tabulated in Table 1 .

Synthetic polymer produced water emulsion was prepared by mixing GLP-100 (0-900 ppm), Dulang crude oil with the initial concentration of $1000 \mathrm{ppm}$, and brine at 14,000 ppm under a shear rate of 13,000 rpm for 10 min using an Ultra Turrax mixer. Next, the emulsion was fed into the flotation column and nitrogen gas was injected through a $40-100-\mu \mathrm{m}$-pore sparger plate for $10 \mathrm{~min}$, as illustrated in Fig. 1. Samples at the water outlet were collected at 2, 6, and $10 \mathrm{~min}$, while oil concentration in the effluents was measured by using the UV-fluorescence method (TD-500D), as portrayed in Fig. 2. 
Besides, $n$-hexane was used to extract oil from the effluents prior to analysis using the TD-500D UV-fluorescence analyser. Based on the oil concentration in effluents outcomes, the efficiency of oil removal was calculated based on Eq. 2, as given in the following:

$\varepsilon=1-\frac{C_{\text {underflow }}}{C_{\text {inlet }}} \times 100$

where $C_{\text {underflow }}$ is oil concentration in the effluent, while $C_{\text {inlet }}$ refers to oil concentration at the inlet.

By using Design Expert 9.0, a total of 32 runs were designed based on factorial design and conducted to examine the effects of GLP-100, gas flowrate, and duration of flotation. The empirical outcomes were later used to develop an equation based on quadratic model in order to establish the correlation between independent and dependent variables. The independent variables in this study are concentration of polymer (ppm) $\left(X_{1}\right)$, gas flowrate $(\mathrm{L} / \mathrm{min})$ $\left(X_{2}\right)$, and duration of flotation (minutes) $\left(X_{3}\right)$, whereas the predicted response of flotation efficiency $(\%)$ is designated as Y. The actual and coded values are given in Table 2.

The equation was validated by using ANOVA, while the coefficients were calculated with Design Expert 9.0. Finally, confirmatory experiments were conducted for verification based on the predicted optimal parameter values. The actual values from the confirmatory experiments were compared with the predicted optimal parameter values, wherein mean values, STD, and absolute average percentage error (AAPE) were calculated.

\section{Results and discussion}

\section{ANOVA statistical analysis}

The results of ANOVA statistical analysis are tabulated in Table 3, and Eq. 3 portrays the efficiency of separation $(Y)$

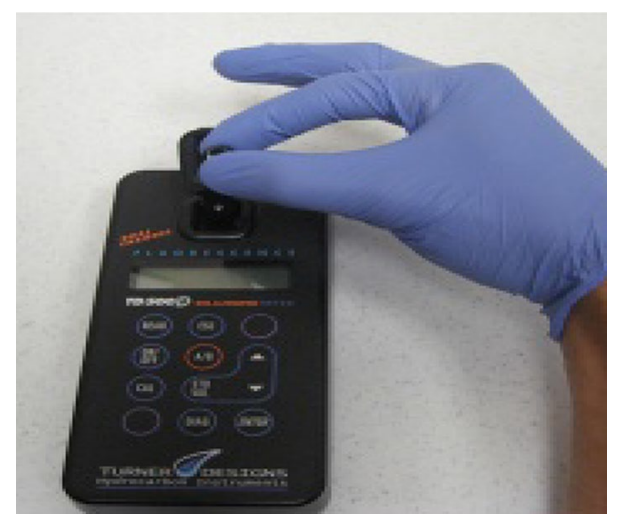

Fig. 2 TD-500D Oil in Water Analyser
Table 2 Parameters and the actual values

\begin{tabular}{|c|c|c|c|c|}
\hline \multirow[t]{3}{*}{ Parameter } & \multirow[t]{3}{*}{ Symbol } & \multicolumn{3}{|c|}{ Parameter level } \\
\hline & & Low -1 & Centre 0 & High +1 \\
\hline & & \multicolumn{3}{|c|}{ Actual value } \\
\hline $\begin{array}{l}\text { GLP-100 concentration } \\
(\mathrm{ppm})\end{array}$ & $X_{1}$ & 0 & 450 & 900 \\
\hline Gas flowrate (L/min) & $X_{2}$ & 1 & 3 & 5 \\
\hline Duration (min) & $X_{3}$ & 2 & 6 & 10 \\
\hline
\end{tabular}

expressed as functions of GLP-100 concentration (ppm) $\left(X_{1}\right)$ and duration of flotation (minutes) $\left(X_{3}\right)$.

$$
\begin{aligned}
Y= & 97.72-8.41 X_{1}+14.61 X_{2}+7.42 X_{3}+19.86 X_{1} X_{2} \\
& -1.40 X_{1} X_{3}-X_{2} X_{3}-9.4 X_{1}^{2}-22.38 X_{2}^{2}-3.19 X_{3}^{2}
\end{aligned}
$$

The statistical analyses displayed that all parameters, GLP-100 concentration, gas flowrate, and durations of flotation, exerted significant effects upon the efficiency of oil removal with $p$ values of $0.0009,0.0001$, and 0.0021 , respectively. The coefficients of $R^{2}$ and $R_{\text {adj }}^{2}$ were 0.9024 and $0.8625 . R^{2}$ value closer to 1 indicates that the predicted values of the model correlate well with the empirical outcomes. As for this study, all the parameters appeared to be significant in this model. Besides, good agreement was attained between the actual and predicted efficiencies of oil removal, as illustrated in Fig. 3. Such exceptional correlation implies that the quadratic model is indeed an excellent representation of the experimental system.

\section{Contour plots}

Contour plots for the measured response were plotted based on the model equations. Figure 4 portrays the contour plots

Table 3 ANOVA of the RSM in estimating the efficiency of oil removal

\begin{tabular}{llll}
\hline & $\mathrm{F}$ & $p$ value & \\
\hline Source & Value & Prob $>F$ & \\
Model & 22.61 & $<0.0001$ & significant \\
$X_{1}$-polymer concentration & 14.56 & 0.0009 & \\
$X_{2}$-gas flowrate & 46.89 & $<0.0001$ & \\
$X_{3}$-duration & 12.09 & 0.0021 & \\
$X_{1} X_{2}$ & 57.72 & $<0.0001$ & \\
$X_{1} X_{3}$ & 0.29 & 0.5984 & \\
$X_{2} X_{3}$ & 0.15 & 0.7057 & \\
$X_{1}^{2}$ & 7.71 & 0.0110 & \\
$X_{2}^{2}$ & 43.70 & $<0.0001$ \\
$X_{3}^{2}$ & 0.89 & 0.3558 \\
\hline
\end{tabular}

A significance of the parameters can be indicated by the $p$-value. $P$-value that is equal or less than 0.05 indicates that a significant difference does exist 


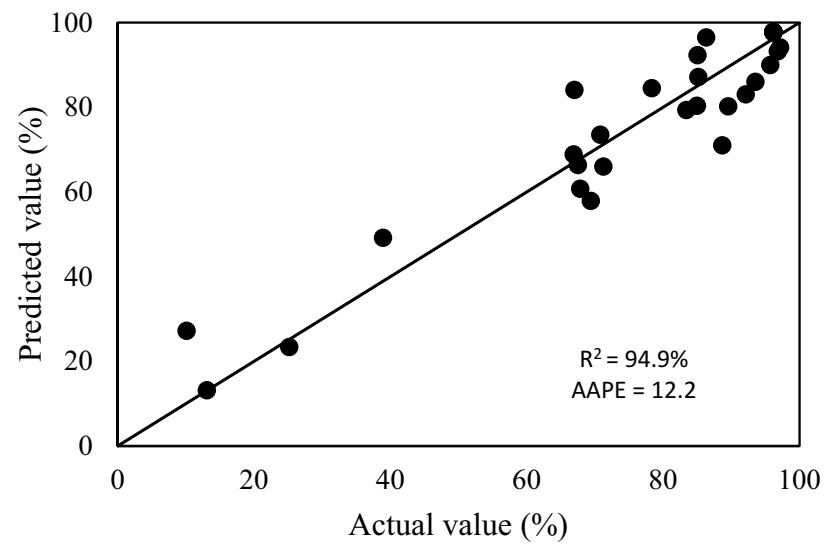

Fig. 3 The actual and predicted values that signify the efficiency of oil removal

for the interaction effect between two parameters: gas flowrate and polymer concentration ( $\mathrm{ppm}$ ). The duration of flotation was kept constant at 2 min (see Fig. 4a), 6 min (see Fig. 4b), and 10 min (see Fig. 4c).

Based on Fig. 4a-c, for gas flowrate at $1 \mathrm{~L} / \mathrm{min}$, increment of polymer concentration from 0 until $900 \mathrm{ppm}$ deteriorated the efficiency of oil removal from the flotation unit. At a lower gas flowrate, the polymer viscosity contributed effectively to the emulsion, when compared to the condition when low volume of gas bubbles was present. The emulsion viscosity from 0 until $900 \mathrm{ppm}$ is displayed in Fig. 5, which signifies increment in emulsion viscosity from $0.5 \mathrm{mPa}$ to $2 \mathrm{mPa}$, along with increasing polymer concentration.

Nevertheless, upon increment of gas flowrate to $3 \mathrm{~L} / \mathrm{min}$, the efficiency of separation hiked to a range of $78-88 \%$ at 2 min of flotation duration (Fig. 4a), 86-96\% at 6 min of flotation duration (see Fig. 4b), and $92-98 \%$ at $10 \mathrm{~min}$ of flotation duration (see Fig. 4c). This reflects that increased gas bubbles volume can attach to oil droplets for better removal. Prior studies also indicated that increment in viscosity increased the size of gas bubbles size, but reduced its breakup rate, so as to allow an efficient separation between oil and water (Mackulak et al. 2009; O'Connor et al. 1990).

When the gas flowrate was hiked to $5 \mathrm{~L} / \mathrm{min}$, the efficiency of oil removal decreased for all flotation durations (see Fig. 4a-c). Based on past studies (Ran et al. 2013; Aumelas and Lecoffre 2017), at a high gas flowrate, more gas bubbles are generated that increase the probability of collision. Nonetheless, when the gas flowrate exceeds the optimum value, a turbulent flow is created and this decreases the separation efficiency. Hence, the gas flowrate at $5 \mathrm{~L} / \mathrm{min}$ exerted a turbulent effect that deteriorated the efficiency of oil removal. Thus, it is imminent to set the optimum flowrate so as to increase the efficiency of oil removal.

Based on the depicted correlation, the optimum predicted values of the flotation parameters at a randomly selected
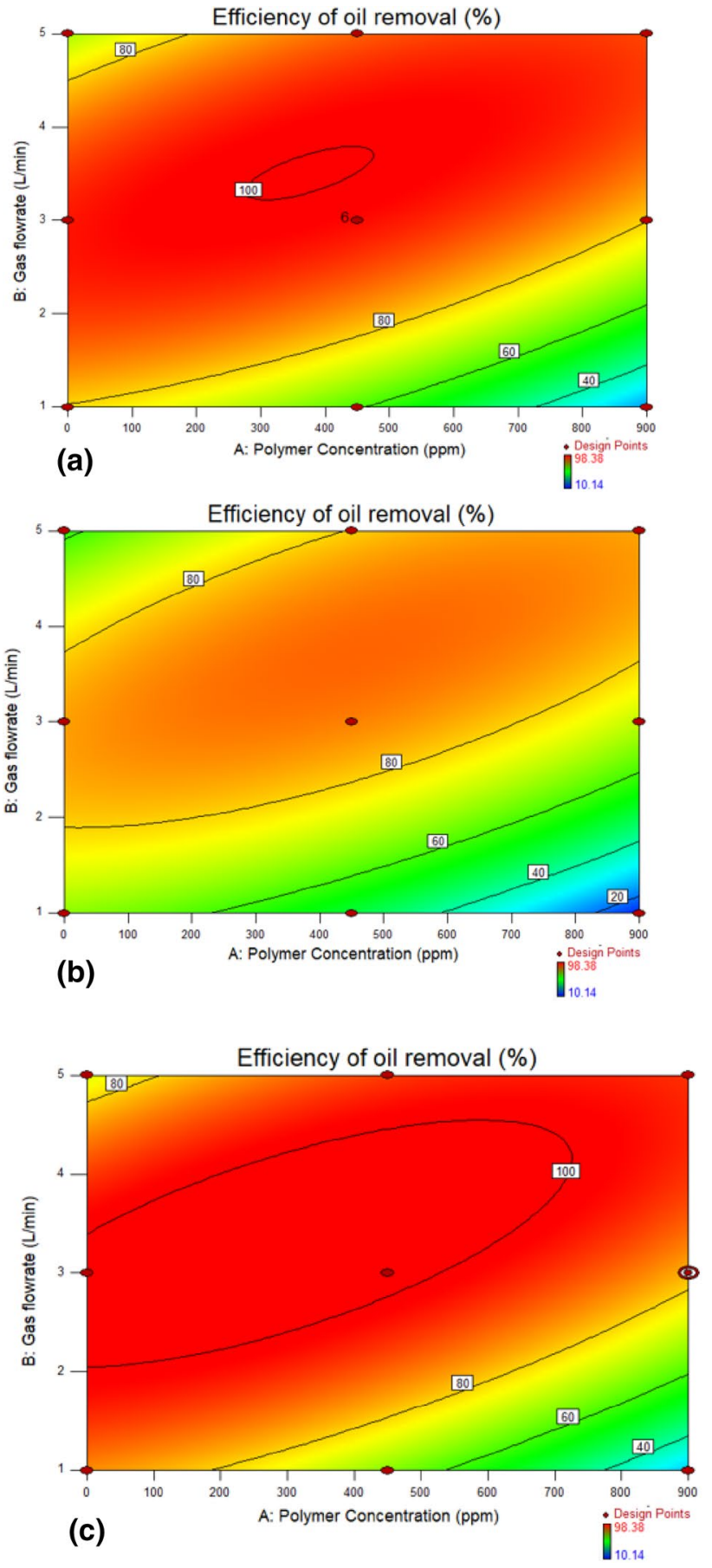

Fig. 4 The effects of polymer concentration and gas flowrate on the efficiency of oil removal at a 2 min of flotation duration, b 6 min of flotation duration, and $\mathbf{c} 10 \mathrm{~min}$ of flotation duration

point which was at $450 \mathrm{ppm}$ polymer concentration are as follows: $3 \mathrm{~L} / \mathrm{min}$ gas flowrate and $6 \mathrm{~min}$ of flotation time with approximately $99 \%$ efficiency. Further experiments were carried out to verify the model. The actual and the predicted values for the optimal conditions are presented in Table 4. The outcomes indicated that the mean value is 


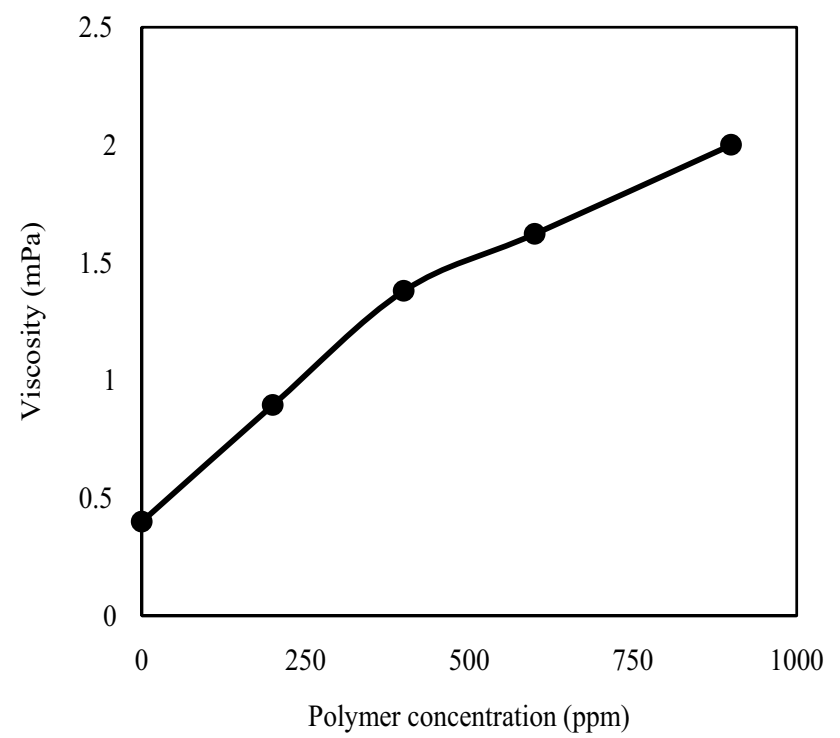

Fig. 5 The effect of polymer concentration on emulsion viscosity

Table 4 The actual, the predicted, and the AAPE values of the confirmatory experiments

\begin{tabular}{llll}
\hline & Actual value $(\%)$ & $\begin{array}{l}\text { Prediction value } \\
(\%)\end{array}$ & AAPE $(\%)$ \\
\hline Point 1 & 98.5 & 100 & 1.523 \\
Point 2 & 99 & 100 & 1.010 \\
Point 3 & 98.7 & 100 & 1.317 \\
Mean & 98.73 & 100 & 1.283 \\
\hline
\end{tabular}

98.7\%, the STD is $0.252 \%$, and the AAPE is $1.28 \%$, signifying exceptional agreement with the predicted results.

\section{Conclusions}

A statistical model was developed to describe the efficiency of oil removal in the presence of a new anionic polymer (produced by PETRONAS), GLP-100, by using the flotation process. It was found that the gas flowrate and the GLP-100 concentration had affected the efficiency of the oil removal significantly. Experiments were carried out to assess the proposed model, and the comparison of the predicted value has matched the experimental value with STD 0.289. It is considered that the model can provide a useful guideline for optimising this flotation unit to maximise the oil removal in the presence of GLP-100 polymer.

Acknowledgements A special thanks to PETRONAS Research Sdn. Bhd, Malaysia, for providing the Dulang crude oil and GLP-100 samples to Centre of Enhanced Oil Recovery (COREOR), Petroleum Engineering.
The authors would like to express their appreciation to Universiti Teknologi PETRONAS for supporting this work under TD-Grant cost centre 0153CB-006.

Open Access This article is distributed under the terms of the Creative Commons Attribution 4.0 International License (http://creativeco mmons.org/licenses/by/4.0/), which permits unrestricted use, distribution, and reproduction in any medium, provided you give appropriate credit to the original author(s) and the source, provide a link to the Creative Commons license, and indicate if changes were made.

\section{References}

Al-Maamari RS, Sueyoshi M, Tasaki M, Kojima K, Okamura K (2014) Polymer-flood produced-water-treatment trials. Oil Gas Facil 3(06):89-100

Atarah JJA (2011) The use of flotation technology in produced water treatment in the oil \& gas industry. Master's thesis, University of Stavanger, Norway

Aumelas V, Lecoffre Y (2017) Improvement of ore recovery efficiency in a flotation column cell using ultra-sonic enhanced bubbles. In: IOP conference series journal of physics conference series

da Silva SS, Chiavone-Filho O, de Barros Neto EL, Foletto EL (2015) Oil removal from produced water by conjugation of flotation and photo-Fenton processes. J Environ Manag 147:257-263

Dalmazzone C, Noïk C, Argillier J-FF (2012) Impact of chemical enhanced oil recovery on the separation of diluted heavy oil emulsions. Energy Fuels 26(6):3462-3469

Eftekhardadkhah M, Aanesen SV, Rabe K, Øye G (2015) Oil removal from produced water during laboratory- and pilot-scale gas flotation: the influence of interfacial adsorption and induction times. Energy Fuels 29(11):7734-7740

Etchepare R, Oliveira H, Azevedo A, Rubio J (2017) Separation of emulsified crude oil in saline water by dissolved air flotation with micro and nanobubbles. Sep Purif Technol 186:326-332

Hosseinzadeh H, Shayegan J, Jalali M (2013) Performance enhancement of dissolved air flotation column in removing low concentrations of heavy fuel oil by adding powdered activated carbon. Desalin Water Treat 51(16-18):3353-3360

Liu S, Zhao X, Dong X, Du W, Miao B (2005) Treatment of produced water from polymer flooding process using a new type of air sparged hydrocyclone. In: Proceedings of SPE Asia Pacific health safety environment conference and exhibition

Mackul'ak T, Prousek J, Olejníková P, Bodík I (2009) Experimental study on bubble lifetime in various liquids. In: Direct, pp 1407-1412

Moosai R, Dawe RA (2003) Gas attachment of oil droplets for gas flotation for oily wastewater cleanup. Sep Purif Technol 33(3):303-314

Multon LM, Viraraghavan T (2008) Removal of oil from produced water by dissolved air flotation. Pract Period Hazardous Toxic Radioact Waste Manag 12(1):25-29

O'Connor CT, Randall EW, Goodall CM (1990) Measurement of the effects of physical and chemical variables on bubble size. Int J Miner Process 28:139-149

Radzi M, Aliff R (2017) Removal of oil droplets from oil-in-water mixtures by dissolved air flotation (DAF). Doctoral dissertation, University of Surrey

Ran J, Liu J, Zhang C, Wang D, Li X (2013) Experimental investigation and modeling of flotation column for treatment of oily wastewater. Int J Min Sci Technol 23(5):665-668

Stewart M, Arnold K (2008) Produced water treating systems

Strickland Jr WT (1980) Laboratory results of cleaning produced water by gas flotation. Soc of Pet Eng J 20(03):175-190

Wang B et al (2011) The effects of oil displacement agents on the stability of water produced from ASP (alkaline/surfactant/polymer) flooding. Colloids Surfaces A Physicochem Eng Asp 379(1-3):121-126

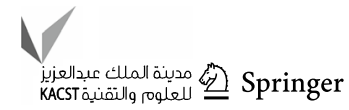


Xu H, Liu J, Wang Y, Cheng G, Deng X, Li X (2014) Oil removing efficiency in oil-water separation flotation column. Desalin Water Treat 53(9):2456-2463
Publisher's Note Springer Nature remains neutral with regard to jurisdictional claims in published maps and institutional affiliations. 